\title{
Variability and Trends of Summer Monsoon Rainfall over Bangladesh
}

\author{
M. N. Ahasan', Md. A.M. Chowdhary² \& D. A. Quadir ${ }^{3}$ \\ ${ }^{1}$ SAARC Meteorological Research Centre (SMRC), Agargaon, Dhaka, Bangladesh \\ E-mail:nazmul_smrc@yahoo.com \\ ${ }^{2}$ Department of Physics, Jahangirnagar University, Savar, Dhaka, Bangladesh \\ ${ }^{3}$ Department of Physics, Uttara University, Dhanmondi Campus, Dhaka, Bangladesh
}

\begin{abstract}
In this paper, the updated rainfall data of 50 years (1961-2010) for 30 selected rain gauge stations of Bangladesh have been used. The data were analyzed to investigate the variability and trends of summer monsoon (JuneSeptember) rainfall over Bangladesh. The possible teleconnection of monsoon rainfall variability with ENSO has also been investigated.
\end{abstract}

Annual profile of the station mean monthly rainfall of Bangladesh shows a unimodal pattern with high rainfall between June-September (monsoon season) with highest in July and low rainfall between December - February with lowest in January. All Bangladesh mean summer monsoon rainfall is $1769.14 \mathrm{~mm}$, standard deviation 209.16 $\mathrm{mm}$ (coefficient of variance $11.82 \%$ ) and annual country average rainfall is $2456.38 \mathrm{~mm}$. Summer monsoon rainfall widely varies over the geographical areas with lowest in central-western part and highest in southeastern part with next highest in northeastern part of the country. The trend analysis shows that the trend of the country average monsoon rainfall is decreasing $(-0.53 \mathrm{~mm} /$ year). The spatial distribution of the trend values indicates that the summer monsoon rainfall exhibits increasing trends at the rate of 5-6 mm/year in the NW region and 3-4 $\mathrm{mm} /$ year in the south-central and extreme SE region. The eastern region exhibits decreasing trends of about -2 to -7 $\mathrm{mm} /$ year with highest ( -6 to $-7 \mathrm{~mm}$ /year) in the east-central part. The time series plot of country average summer monsoon rainfall shows the inter-annual variability in the timescales of 2-3 years and 4-6 years. The time series of 5 year moving average reveals existence of low frequency variability of timescales of 9-14 years. The time series of Bangladesh monsoon rainfall shows that there were 11 strong monsoon years and 8 weak monsoon years within the periods of 1961-2010 (50 years). The analysis of the decadal mean rainfall shows that the decades 1961-1970 and 1981-1990 were wet and the decades 1971-1980, 1991-2000 and 2001-2010 were dry. Floods in Bangladesh result from the excess rainfall occurring both inside and outside the country. Summer monsoon rainfall is characterized by active and weak (break) spells, which are associated with the fluctuation of monsoon rainfall in the time scales of 20-25 and 40-50 days. Such fluctuations are caused due to north-south movement of the monsoon trough. The fluctuations in the time scales of 4-7 and 10-14 days are associated with the formation of low pressure systems over the head Bay. The possible atmospheric teleconnections of summer monsoon rainfall with ENSO have also been investigated. It is found that there is strong impact of ENSO on the monsoon system of subcontinent scale, though the relationship is weak in case of Bangladesh. The variability of Bangladesh rainfall has been investigated with respect to that for Nepal, Bhutan and the neighbouring sub-divisional regions of India. The results show that Bangladesh rainfall has positive correlation with that of the Indian regions of Naga-Monipur-Mizo-Tripura, 
Sub Himalayan West Bengal and Sikkim, and Bhutan. The above analysis shows the homogeneity of rainfall activities over these areas. Orissa shows negative correlation with Bangladesh.

\section{Keywords: Rainfall, Variability, Summer Monsoon, ENSO, Trend}

\section{INTRODUCTION}

Bangladesh is an agricultural country. Being situated in the monsoon region, its economy is dependent on the activities of monsoon. The summer monsoon is the main rainy season in Bangladesh which accounts for about 72 percent of the annual rainfall during summer monsoon season (Ahasan et al, 2008). Agriculture is the mainstay of the economy in Bangladesh and the country largely depends on the rainfall from the summer monsoon. The life of all inhabitants of Bangladesh directly and indirectly depends on the summer monsoon rainfall.

The fertility of farmland as well as the stability of land resources depend heavily upon the activities of the summer monsoon. Most of development endeavours especially those of physical infrastructure like roads, flood control dams, irrigation canals and so on are dictated by the monsoon and most of natural disasters are also associated with the behavior of the monsoon. Thus the economy of the country and fate of the people are closely tied up with the good monsoon rain between June to September and it acts as a life line to the agrarian society of the region. Hence, the joys and sorrows of the millions of peoples of Bangladesh are linked with the variability of the summer monsoon rainfall.

Moreover the monsoon season is characterized by the occurrence of severe floods due to heavy rainfall causing extensive damage to crops, livestocks and properties associated with loss of valuable lives. As per the records, the floods of 1984, 1987, 1988, 1998, 2004 and 2007 were unprecedented and caused tremendous loss of agricultural crops, infrastructures and dwelling houses, which affected the economy and livelihood of the people. On the other hand, the failure of the monsoon rain causes severe droughts resulting to major crop failures. Success of farming in Bangladesh is heavily dependent on the timely arrival of monsoon rainfall and its distrbution.

Some earlier studies have shown that the rainfall of Bangladesh have been increasing during the recent decades (Chowdhury et. al., 1997 and Karmaker et. al., 2000). The study by Nehrin et. al. (1998) reported the existence of temporal oscillations with timescales of 2-3 years, 4-7 years and around 20 years. The variability of rainfall ( $>22 \mathrm{~mm} /$ day) for summer has been studied by Mannan and Karmakar (2008). An analysis on summer monsoon rainfall over Bangladesh has been done by Ahasan et al. (2008), which focused on flood disasters. However, the above studies are not up-to-date and are subject to further confirmation through more detail study.

Hence, the present study focuses on the spatial and temporal (intra-seasonal and inter-annual) variability and trends of summer monsoon rainfall in more details over Bangladesh by using up-todate data sets covering the period 1961-2010. The study also considers the investigation of the relationship of the monsoon rainfall variability with ENSO activity. The correlation analysis has also been performed between the rainfall of Bangladesh and that of Nepal and Bhutan and the nearby sub-divisional rainfall regions of India. The 
results will improve the general understanding of the summer monsoon rainfall variability and trends over Bangladesh.

\section{DATA USED AND METHODOLOGY}

The observed daily and monthly rainfall data of 30 selected rain gauge stations of Bangladesh during the period 1961-2010 (50 years) were collected from the Climate Division of Bangladesh Meteorological Department (BMD). The stations are selected on the basis of uniform spatial distribution and availability of maximum data length and data accuracy. The data were subjected to a visual inspection and the suspected data were deleted and marked as blank. These suspected data points and missing entries were filled up by inverse square distance weighted interpolation technique. The location of the rain gauge stations selected for this study is shown in Figure 1.

From the meteorological point of view, there are four climatic seasons in Bangladesh. They are: Winter (December-February), Pre-monsoon (MarchMay), Monsoon (June-September) and Postmonsoon (October-November). This classification of seasons, as mentioned above, has been considered in many reports of SMRC and BMD. It may be noted here that for the computation of seasonal values for the winter season, the data of December for one year has been used with the data of January and February of the following year to represent the winter value of the following year. Throughout this study, the term winter and monsoon simply means northeast winter monsoon and southwest summer monsoon respectively. The term all-Bangladesh (also referred as country average) rainfall means the average rainfall of all the selected stations of Bangladesh.

El-Nino/Southern Oscillation (ENSO) data have been downloaded from the website (http://ggweather.com/enso/oni.htm) of Golden Gate Weather Services, Canada based on which the El Nino and La Nina years were identified and collated in the tabular form (Table-1).

Table-1: List of the EI Nino and La Nina years

\begin{tabular}{|c|c|c|c|c|c|}
\hline \multicolumn{3}{|c|}{ El Nino } & \multicolumn{3}{c|}{ La Nina } \\
\hline Weak & Moderate & Strong & Weak & Moderate & Strong \\
\hline 1963 & 1986 & 1965 & 1962 & 1964 & 1973 \\
1968 & 1987 & 1972 & 1967 & 1970 & 1975 \\
1969 & 1994 & 1982 & 1971 & 1998 & 1988 \\
1976 & 2002 & 1991 & 1974 & 1999 & \\
1977 & & 1997 & 1984 & 2007 & \\
2004 & & 2009 & 1995 & 2010 & \\
2006 & & & 2000 & & \\
\hline
\end{tabular}

Rainfall data of India has been collected from the website (http://www.tropmet.res.in/) of Indian Institute of Tropical Meteorology (IITM), Pune, India. Rainfall data of Bhutan and Nepal have been collected from the archive of SMRC.

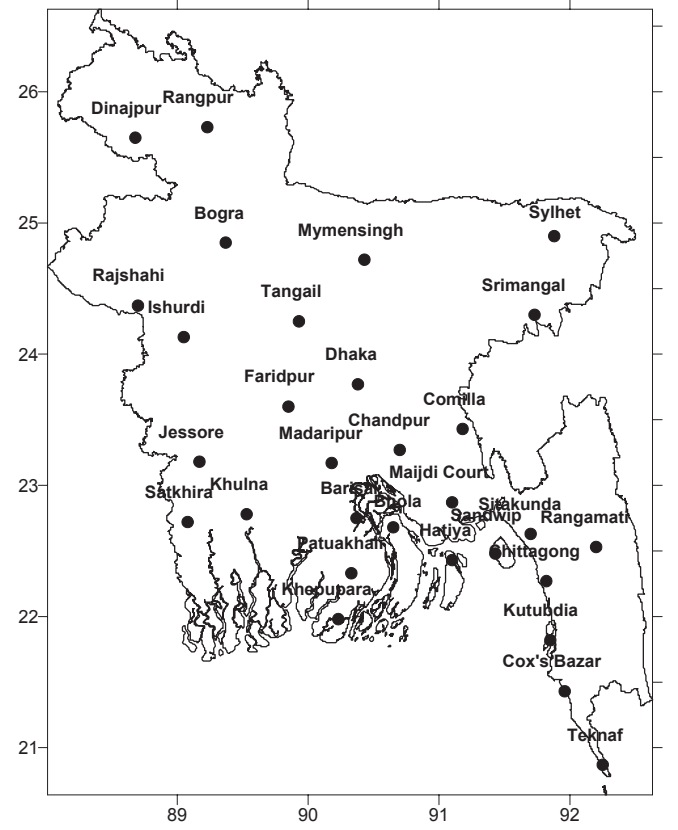

Figure 1: The location of 30 selected rain gauge stations over Bangladesh. 


\section{RESULTS AND DISCUSSION}

The monthly, seasonal and annual rainfall data are constructed on the basis of the daily rainfall data. Bangladesh is situated at the interface of two different environments, with the Bay of Bengal to the South and Himalayas to the north. Due to its geographical position, Bangladesh experiences highest amount of country average monsoon and annual rainfall among SAARC countries (Devkota, 2006). The rainfall of Bangladesh is mainly governed by the activities of southwest summer monsoon system (i.e., position and intensity of monsoon trough), tropical cyclonic disturbances, local land origin weather systems (land depressions, thunderstorms and mesoscale convective systems) and sub-tropical western disturbances. The Khasi-Jaintia-Garo hill complex and the plateau of Shillong and Arakan Mountains and Mizo hills play important role in modifying the rainfall pattern in northeast and southeast part of the country.

The results of the present study on the variability of summer monsoon rainfall of Bangladesh have been discussed in the subsequent sub sections.

\subsection{ONSET AND WITHDRAWAL DATES OF SUMMER MONSOON RAINFALL}

The onset and withdrawal dates of summer monsoon in Bangladesh vary from year to year. The summer monsoon generally begins over southeastern part of Bangladesh by late May or early June and withdraws by the middle of October. The climatological dates of onset of monsoon were fixed by Bangladesh Meteorological Department (BMD) on the basis of sharp increase in pentad rainfall. The climatological (normal) date of onset of monsoon over southeastern part of Bangladesh is June 1. Indian Meteorological Department (IMD) also fixed the climatological date of onset of monsoon over south Kerala of India as June 1. A detailed work on onset and withdrawal dates of summer monsoon over Bangladesh has been done by Ahmed and Karmakar (1993). As per their studies, the mean onset dates of summer monsoon in Bangladesh in the extreme south-eastern coastal part and in the extreme north-western part are 2 June and 15 June respectively. The mean withdrawal dates of the summer monsoon from the northwestern and south-eastern part are 30 September and 17 October respectively. Standard deviations of the onset and withdrawal dates in different parts vary from 7 days to 10 days and the zone of high variability in both cases being located in the area that extends from southeastern to northeastern part of the country. The mean duration of summer monsoon varies from about 107 days in the extreme northeastern to about 137 days in the extreme southeastern part of the country. Spatial distribution of onset and withdrawal dates of summer monsoon over Bangladesh is shown in Figures 2(a-b).

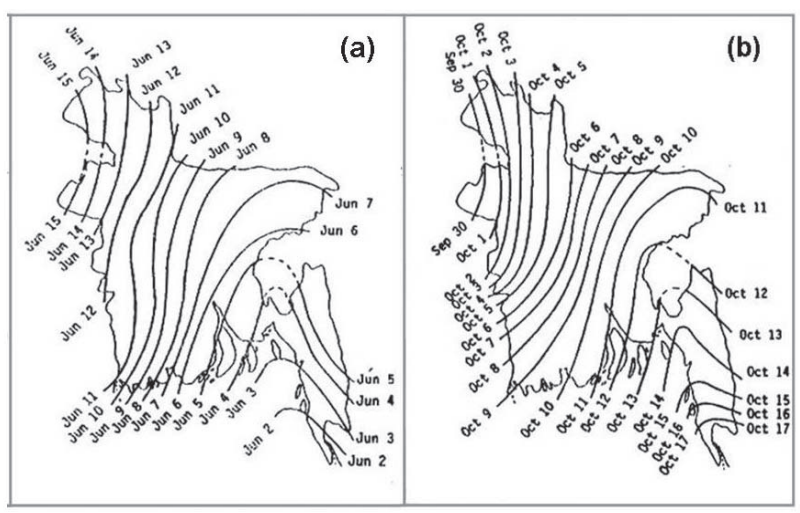

Figure 2: Spatial distribution of (a) onset dates of southwest summer monsoon and (b) Withdrawal dates of southwest summer monsoon over Bangladesh (Ahmed and Karmakar, 1993). 


\subsection{ANNUAL PROFILE OF THE MONTHLY AND SEASONAL TOTAL RAINFALL}

The all-Bangladesh annual profile of the monthly and seasonal total rainfall has been calculated from the rainfall data of 30 selected stations during the period 1961-2010 and presented as bar diagram in Figure 3 and Figure 4 respectively. The annual profile of the monthly and seasonal total rainfall, percentage of the annual, standard deviation and coefficient of variation have also been calculated and presented in Table-2.

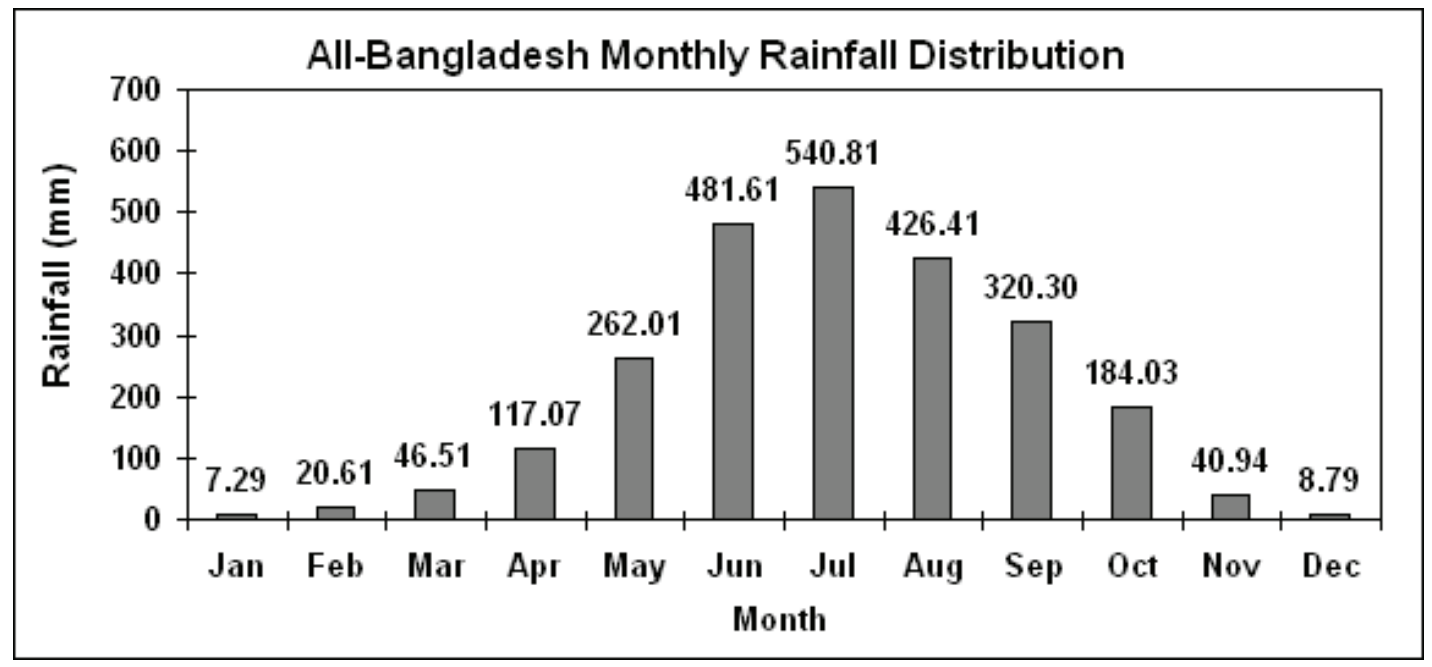

Figure 3: All-Bangladesh annual profile of the monthly total rainfall $(\mathrm{mm})$ during the period 1961-2010.

From the Figure 3, it is found that the country experiences unimodal rainfall pattern throughout the year. The highest amount of country average monthly rainfall occurs in July followed by June and August, and lowest amount of rainfall occurs in January followed by December and February. Rainfall increases gradually from the month of January to July and then decreases.

Analysis of the individual station's data revealed that among 30 stations, 25 stations of the country experience maximum amount of rainfall in July, rest 5 stations located in the south, southwest and northeastern part of the country experience highest amount of rainfall in June. These stations are Bhola, Barisal, Faridpur, Khulna and Srimangal. Some neighbouring stations of these five stations though show highest rainfall in July, but close to the June rainfall. Besides, all stations of the country experiences unimodal rainfall pattern throughout the year. Most of the rainfall is obtained from the monsoon activities.

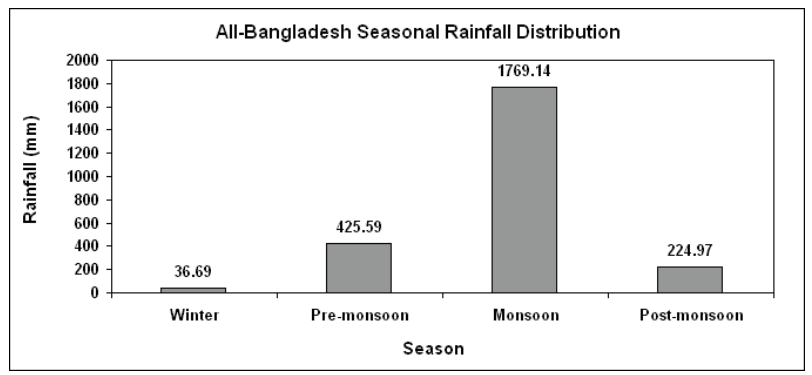

Figure 4: All-Bangladesh seasonal profile of the annual rainfall (mm) during the period 1961-2010. 
From the Figure 4, it is found that the all-Bangladesh seasonal rainfall shows a unimodal pattern with highest amount of rainfall in the monsoon season which is $1769.14 \mathrm{~mm}$ that constitute $72 \%$ of the annual rainfall. The annual rainfall amounts to $2456 \mathrm{~mm}$. The standard deviation of monsoon rainfall is $209.16 \mathrm{~mm}$ and co-efficient of variance is $11.82 \%$.

It is found that the lowest rainfall amounting to $36.69 \mathrm{~mm}$ (1.5\% of annual) is obtained in winter season. Second highest rainfall occurs in premonsoon season which is $425.59 \mathrm{~mm}(17.3 \%)$. Thunderstorm activities during the pre-monsoon season make its rainfall higher than post monsoon rainfall, the latter being $224.97 \mathrm{~mm}(9.2 \%)$. The station-wise analysis shows that the highest amount of monsoon rainfall occurs at Teknaf (3424 mm) and lowest occurs at Rajshahi (1109 $\mathrm{mm})$. Sylhet receives the second highest rainfall during summer monsoon season which amounts to $2712 \mathrm{~mm}$.

Table-2: All-Bangladesh annual profile of the monthly and seasonal total mean rainfall $(\mathrm{mm})$, percentage of the annual rainfall (\%), standard deviation $(\mathrm{mm})$ and co-efficient of variation $(\%)$.

\begin{tabular}{|l|c|c|c|c|}
\hline Month /Season & Mean $(\mathbf{m m})$ & $\begin{array}{c}\text { Percentage } \\
(\mathbf{\%})\end{array}$ & $\begin{array}{c}\text { Standard } \\
\text { Deviation }(\mathbf{m m})\end{array}$ & $\begin{array}{c}\text { Co-efficient of } \\
\text { Variance (\%) }\end{array}$ \\
\hline January & 7.29 & 0.30 & 2.18 & 29.97 \\
\hline February & 20.61 & 0.84 & 7.19 & 34.88 \\
\hline March & 46.51 & 1.89 & 20.87 & 44.87 \\
\hline April & 117.07 & 4.77 & 58.72 & 50.16 \\
\hline May & 262.01 & 10.67 & 84.96 & 32.43 \\
\hline June & 481.61 & 19.61 & 178.20 & 37.00 \\
\hline July & 540.81 & 22.02 & 217.81 & 40.27 \\
\hline August & 426.41 & 17.36 & 162.80 & 38.18 \\
\hline September & 320.30 & 13.04 & 65.10 & 20.33 \\
\hline October & 184.02 & 7.49 & 40.75 & 22.14 \\
\hline November & 40.95 & 1.67 & 21.10 & 51.51 \\
\hline December & 8.79 & 0.36 & 2.12 & 24.11 \\
\hline Winter & 36.69 & 1.49 & 25.33 & 69.03 \\
\hline Pre-monsoon & 425.59 & 17.33 & 134.17 & 31.53 \\
\hline Monsoon & 1769.14 & 72.02 & 209.16 & 11.82 \\
\hline Post-monsoon & 224.97 & 9.16 & 95.22 & 42.33 \\
\hline Annual & 2456.38 & 100.00 & 270.62 & 11.02 \\
\hline
\end{tabular}

\subsection{SPATIAL DISTRIBUTION OF MEAN SUMMER MONSOON RAINFALL}

The mean monsoon rainfall over Bangladesh has been calculated for 30 selected stations using the data covering 1961-2010. The spatial distribution of these station-wise mean monsoon rainfall have been presented in Figure 5. The analysis shows that the summer monsoon rainfall varies widely over different parts of the country. Relatively lower amount of rainfall occurs in the west-central, central and east-central part of the country, where the rainfall varies from 1200-1400 $\mathrm{mm}$ and increases from west to east. The rainfall 
is high over the northeastern, southern and the southeastern parts; the latter experiences the highest monsoon rainfall (3200-3400 mm). This is due to enhanced activities of cyclonic disturbances and thunderstorm over this region. The Arakan Mountains and the Mizo hills play an important role for increasing rainfall at Teknaf and Cox's Bazar area i.e. southeastern part of the country. The second highest monsoon rainfall occurs in the northeastern part of the country (2400-2600 mm). This is due to the trapping of the moisture laden monsoon flow in the orographic convergence of the northern and eastern hill slopes. This interesting to note that Sylhet is situated near Cherapunji of Shellong plateau which is one of the areas of the world with highest rainfall.

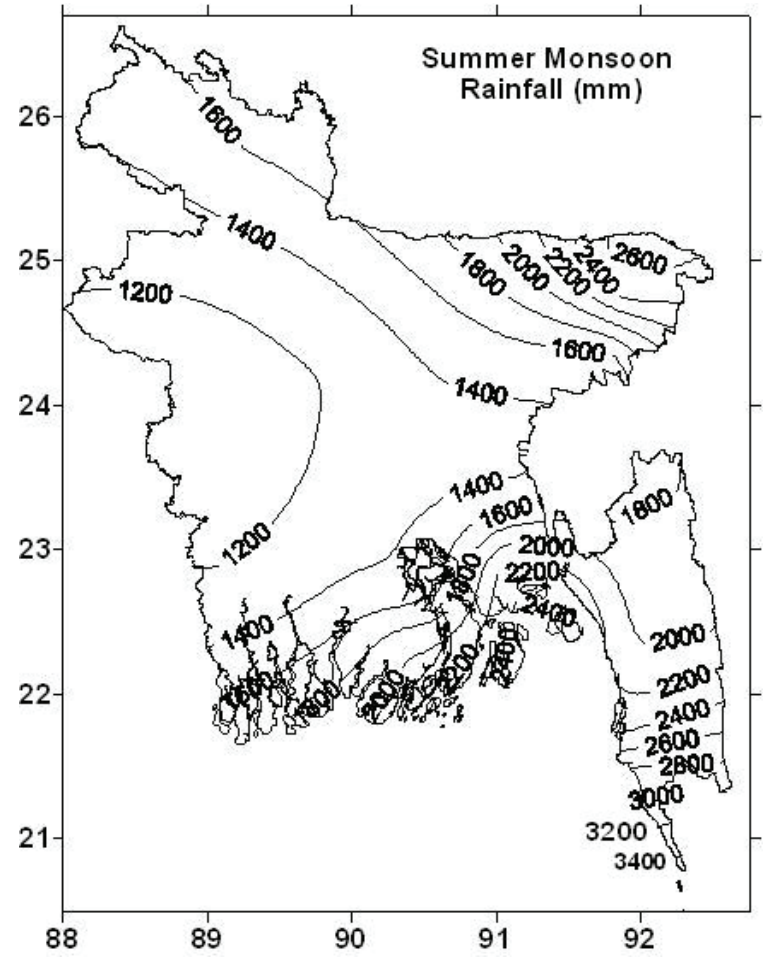

Figure 5: Spatial distribution of summer monsoon rainfall $(\mathrm{mm})$ over Bangladesh during the period 1961-2010.

\subsection{SPATIAL DISTRIBUTION OF PERCENTAGE OF ANNUAL RAINFALL DURING MONSOON SEASON}

The summer monsoon rainfall for each of the stations has been expressed as percentage of annual rainfall and the spatial distribution of this percentage over Bangladesh is shown in Figure 6. This figure brings out the rainfall concentration during the four months (JJAS) of the season. Extreme southeast part of Bangladesh receive more than $82 \%$ of the annual rainfall during monsoon season which is the highest over Bangladesh and Lowest percentage of annual rainfall during monsoon season occurs at Srimangal over Bangladesh which is about $60-62 \%$. Extreme northeast part of Bangladesh receives about $66 \%$ of the annual rainfall during monsoon season. Extreme northwest and southwest part of Bangladesh receive about $72-74 \%$ of the annual rainfall during monsoon season. This indicates that Bangladesh is getting major portion of the annual rainfall during the summer monsoon season.

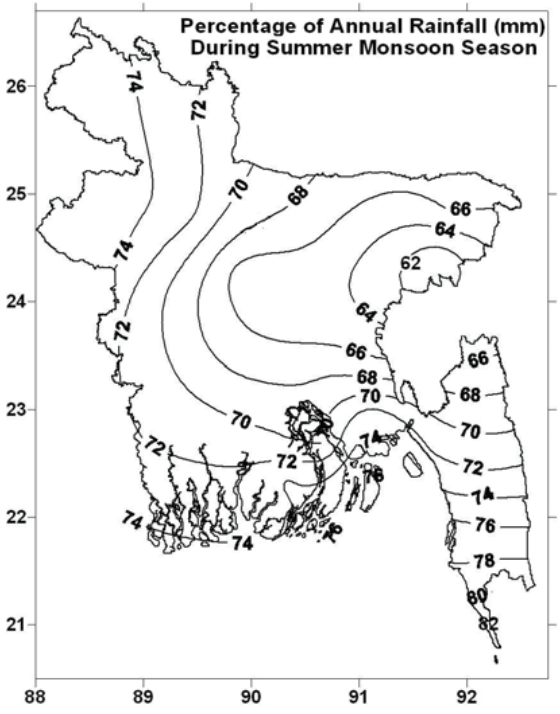

Figure 6: Spatial distribution of percentage of annual rainfall $(\mathrm{mm})$ during summer monsoon over Bangladesh during the period 1961-2010. 


\subsection{SPATIAL DISTRIBUTION OF STANDARD DEVIATION AND COEFFICIENT OF VARIANCE OF SUMMER MONSOON RAINFALL}

The standard deviation and the coefficient of variation (ratio of standard deviation and mean expressed as percentage) which are relative measure of variation of the monsoon rainfall have been computed for all the 30 stations and the spatial distribution of the same over the country are shown in Figure 7(a, b). From Figure 7(a), it is found that the standard deviation is high $(600-650 \mathrm{~mm})$ over the southeast region and low $(250-300 \mathrm{~mm})$ over the west-central region of Bangladesh. The standard deviation varies from $350-450 \mathrm{~mm}$ over the east-

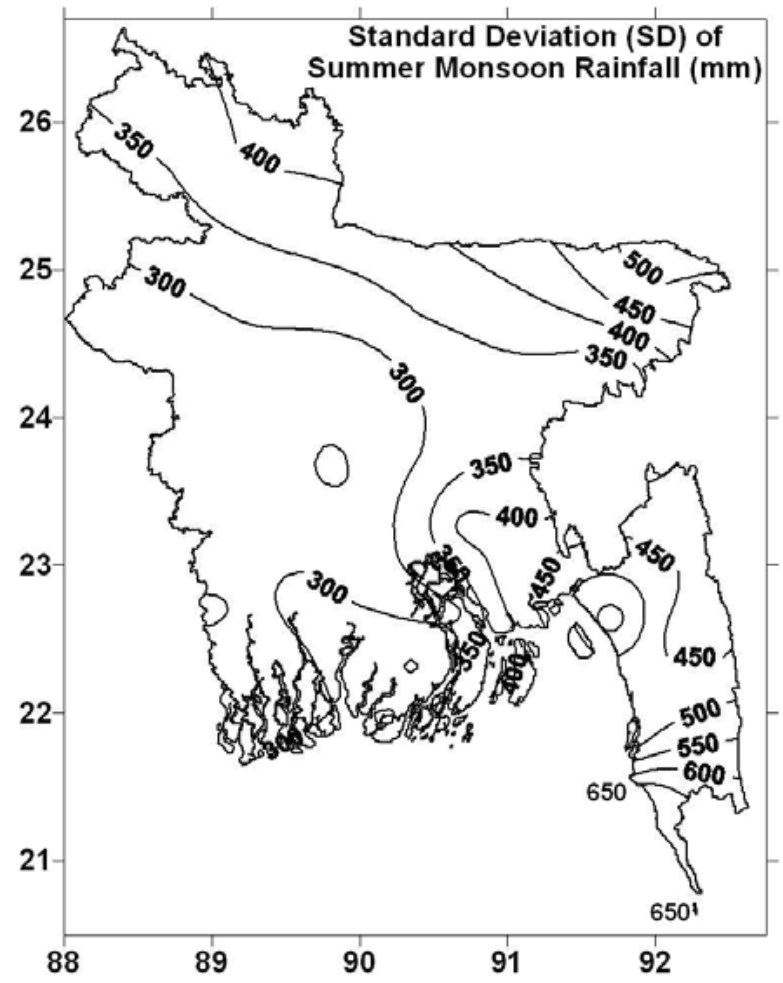

central region of the country. In central part of the country it varies from $300-350 \mathrm{~mm}$.

The coefficient of variation $(\mathrm{CV} \%)$ is another suitable measure of the variability of rainfall which has been shown in Figure 7(b). It is found that high CV which varies from $24 \%$ to $28 \%$ is observed in the east-central part of the country. Very low CV which varies from $16 \%$ to $18 \%$ is observed over the southern part except extreme southeast part of the country. The CV of $24 \%$ is observed at the extreme northwest and west-central part, and $20-22 \%$ at the southeast and northeast part of the country during the monsoon season. To some extent, the high CV is observed over the low rainfall areas and low $\mathrm{CV}$ over the high rainfall areas.

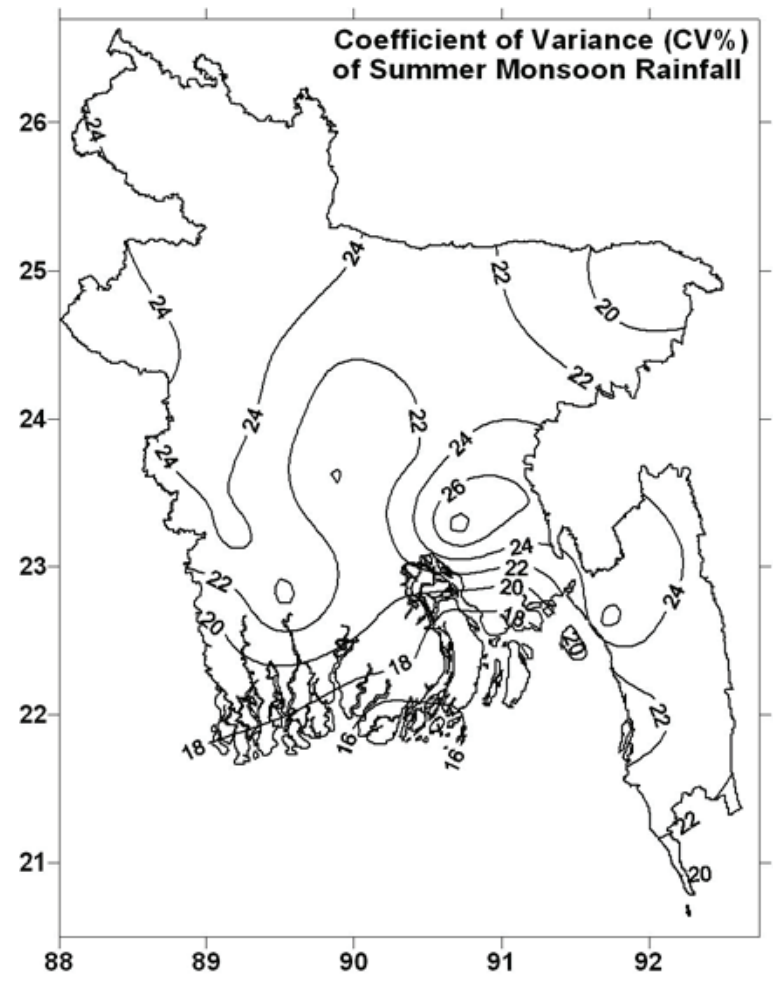

Figure 7(a, b): Spatial distribution of (a) standard deviation (mm) and (b) coefficient of variance (CV\%) of summer monsoon rainfall over Bangladesh during the period 1961-2010. 


\subsection{VARIABILITY AND TRENDS OF SUMMER MONSOON RAINFALL}

An attempt has been made to study the interannual and inter-decadal variability and trends of summer monsoon rainfall over Bangladesh during the period 1961-2010.

One of the most important features of the summer monsoon rainfall is its inter-annual variability. Inter-annual variability of monsoon rainfall was revealed in the inter-annual time series plots of the anomalies of All-Bangladesh monsoon rainfall for the period 1961-2010 as solid thick line and the 5 year moving average as dash/broken line (Figure 8). The five year moving average effectively filters the high frequency mode of variations with period 5 years or less when the decadal modes of variations are more clearly manifested. During the period 1961-2010, there have been 8 occasions when monsoon rainfall was deficient (below $-10 \%$ of long period average) and 11 occasions when the monsoon rainfall was excess (above 10\% of long period average) [also see in Figure11 (a)]. It is also found that the highest amount of rainfall occurred in 1987 (higher than 2 standard deviation above mean) in Bangladesh followed by the year 1984 and 2004 (higher than 1.5 standard deviation above mean) when Bangladesh experienced big floods. The lowest amount of rainfall occurred in Bangladesh in 1980 followed by the year 1972, 1992 and 1994. Though the years 1988, 1998 and 2007 were the worst flood years in Bangladesh, but the monsoon rainfall was not much excess in those years. This indicates that floods in Bangladesh occur not only due to rainfall inside the Bangladesh, but also by the rainfall in the upstream. It is mentioned that the runoff of the rainwater over 92\% (62\% India, 18\% China, $8 \%$ Nepal, 4\% Bhutan) of the catchment areas lying outside Bangladesh and the runoff generated inside Bangladesh over the rest $8 \%$ of the catchments jointly flow through Bangladesh contributing to floods (Hughes et al.,1994).

The temporal plot of summer monsoon rainfall shows the small scale inter-annual variability with small timescale of 2-3 and 4-6 years in the solid thick line plot and decadal time scale of 9-14 years as revealed in the dash/broken line plot of 5 year moving average (Fig.8). There are variations of multi-decadal scale which is revealed through the bar diagram plots of decadal mean of allBangladesh monsoon rainfall calculated for the decades 1961-1970, 1971-1980, 1981-1990, 19912000, 2001-2010 (Fig.9). The summer monsoon was in the wet decade during 1961-1970 and 19811990 and in the dry decade during the 1971-1980, 1991-2000 and 2001-2010. This clearly indicates the multi-decadal scale of variability of the summer monsoon.

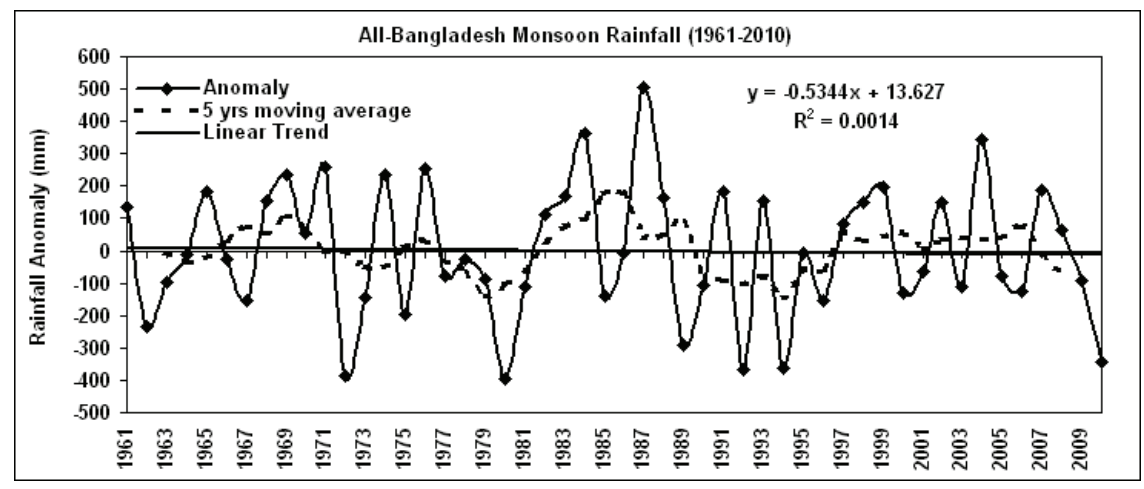

Figure 8: Inter-annual small scale and large scale variability of all-Bangladesh summer monsoon rainfall and linear trend analysis during the period 1961-2010. 


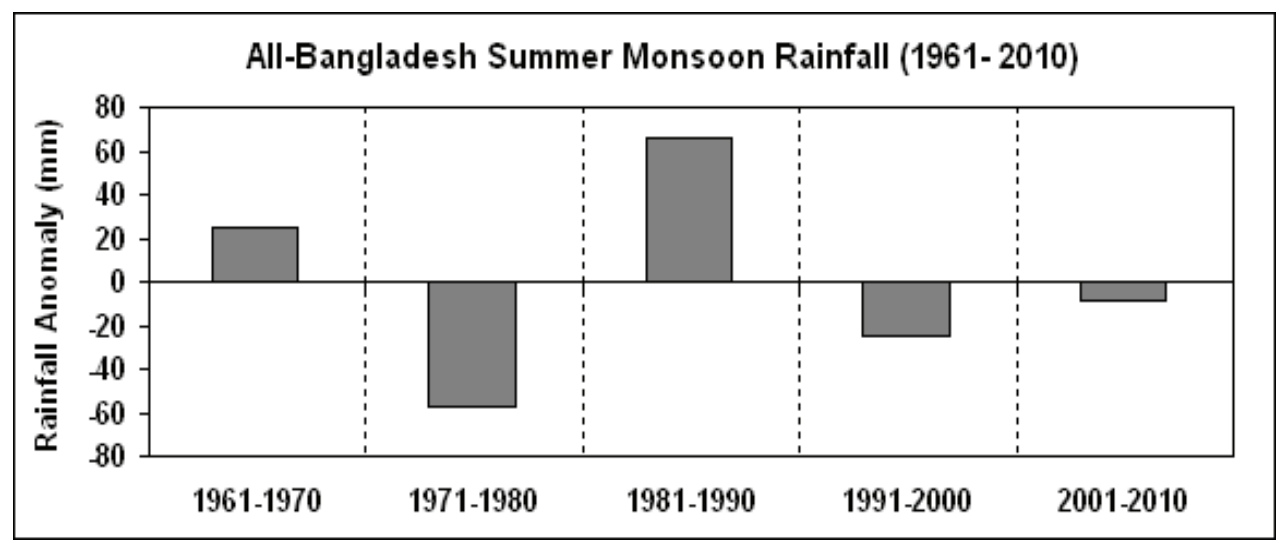

Figure 9: Inter-decadal variability of summer monsoon rainfall (mm) over Bangladesh during the period 1961-2010.

The spatial distribution of linear trend values of summer monsoon rainfall for 30 selected stations during the period 1961-2010 are presented in Figure 10. It is found that the monsoon rainfall shows highest increasing trend at the rate of about 5-6 mm/year over northwest part of Bangladesh and decreasing trend at the rate of about -6 to -7 $\mathrm{mm} /$ year over the east-central part of the country. The eastern part of the country exhibits decreasing trend ( -2 to $-7 \mathrm{~mm} /$ year) except extreme southeast part of Bangladesh. The southwest, south-central and extreme southeastern part of the country show increasing trend at the rate of about 3-4 mm/year. Sylhet which is one of the highest rainfall regions of Bangladesh exhibits decreasing trend at the rate of about -2 to $-3 \mathrm{~mm} /$ year. The central and west-central part of the country does not show any significant increasing or decreasing trend except Ishurdi, where the trend of monsoon rainfall is observed as -2 to $-3 \mathrm{~mm} /$ year. The station Jessore situated to the south of Ishurdi has as increasing trend of 2-3 $\mathrm{mm} /$ year.

The trend of all-Bangladesh summer monsoon rainfall is shown in Fig.8. All-Bangladesh monsoon rainfall exhibits weak decreasing trend at the rate of $-0.53 \mathrm{~mm} / \mathrm{year}$. The trends calculated for other seasons (figures are not shown) show the highest increasing trend of $1.74 \mathrm{~mm} /$ year in the pre-monsoon season and relatively small trend of $0.06 \mathrm{~mm} /$ year in the winter season. Post-monsoon rainfall shows the increasing trend at the rate of $0.65 \mathrm{~mm} /$ year. The annual rainfall shows an increasing trend of $1.92 \mathrm{~mm} /$ year.

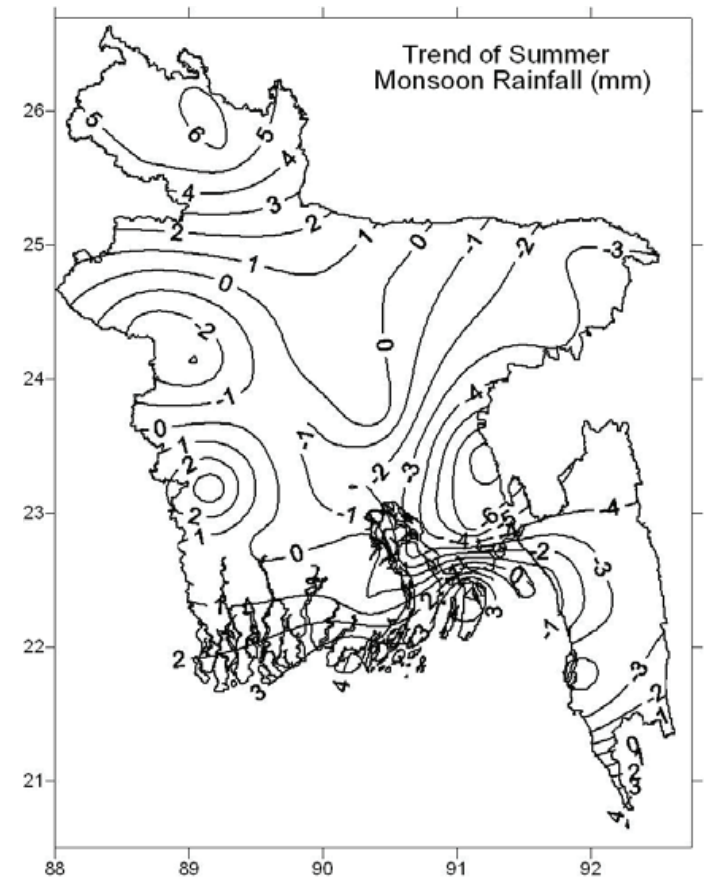

Figure 10: Spatial distribution of linear trend value of summer monsoon rainfall $(\mathrm{mm})$ over Bangladesh during the period 1961-2010. 


\subsection{ENSO AND ITS RELATIONSHIP WITH SUMMER MONSOON RAINFALL}

An attempt has been made to study the relationship between ENSO and summer monsoon rainfall over Bangladesh and India. For this purpose, percentage departure from long period average of all-Bangladesh monsoon rainfall during 1961-2010 has been calculated and shown in Figure 11(a). The same for India during the period 1961-2006 is shown in Figure 11(b). In order to investigate as how the ENSO events impact on the monsoon rainfall variability, the years with warm episodes (El Nino years) and cold episodes (La Nina years) are identified by black and stripe bars respectively in the plots. Only strong and moderate El Nino and La Nina years are considered in this study. It has been found from Figure 11(a) that 6 years out of 10 strong and moderate La-Nina years have positive departure of rainfall and 4 years have negative departure of rainfall in Bangladesh. On the other hand, 5 years out of 9 strong and moderate El-Nino years have positive departure of rainfall and 4 years have negative departure of rainfall. It emerges that the years of excess rainfall and deficit rainfall vis-à-vis the cold episodes and warm episodes are haphazardly distributed and do not follow any systematic pattern, which indicates that the variability of monsoon rainfall of Bangladesh is more or less indifferent to ENSO episodes.

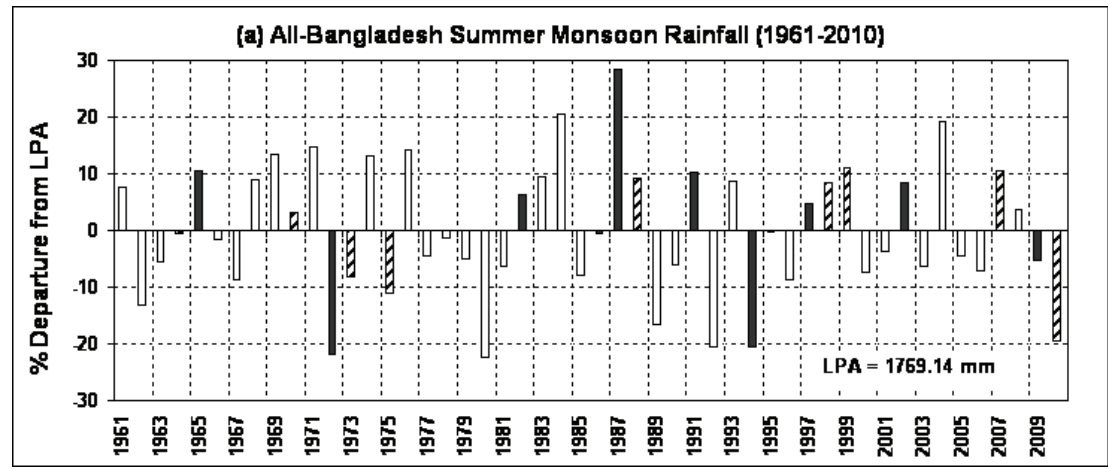

Figure 11(a): The all-Bangladesh inter-annual variability summer monsoon seasonal rainfall (mm) percentage departure from long period average (1961-2010) of Bangladesh. the year of warm episodes of ENSO events are shown by black bars and those of cold episodes by stripe. The warm and cold episodes refer to the El Nino and La Nina events.

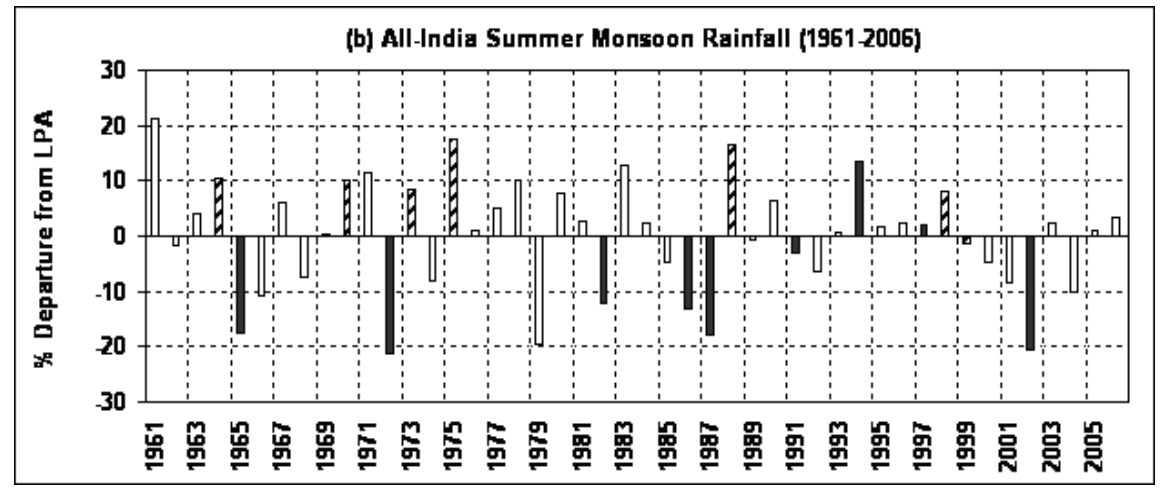

Figure 11(b): The all India summer monsoon rainfall (JJAS) percentage departures from normal; warm and cold episodes refer to the EI Nino and La Nina events which are shown by black bars and stripe bars respectfully (IMD). 
It is interesting to note that the year 1987, which was a significant El-Nino year, stands out as the year of maximum excess rainfall in Bangladesh during the period 1961-2010. In sharp contrast, 1987 was a severe drought year in India (country as a whole). Likewise 2002, which were also a warm episode and a severe drought year in India, turned out to be a year of significantly positive departure of rainfall in Bangladesh. 1998 was another year of excess rainfall which belongs to a cold episode. For India, about $50 \%$ of the wet years coincided with La Nina episodes and $50 \%$ of the dry years coincided with the El Nino episodes (Figure 11(b)). There was only one El Nino case with high excess rainfall in1994 but no La Nina case with strong deficit rainfall was observed. This indicates that the ENSO events do have impacts on monsoon systems on large subcontinent scale but the relationship of ENSO with Bangladesh monsoon is rather weak.

\subsection{CORRELATION COEFFICIENTS OF SUMMER MONSOON RAINFALL}

The correlation coefficients (CCs) of allBangladesh summer monsoon rainfall with the time series of that of Nepal, Bhutan and 7 selected sub-divisional regions of India (see Table-3) have been calculated. The locations of Nepal, Bhutan and sub-divisional rainfall regions of India are shown in Figure 12. The selected sub-divisions are Assam \& Meghalaya, Naga-Manipur-Mizoram \& Tripura, Sub-Himalayan West Bengal \& Sikkim, Gangetic West Bengal, Orissa, Jharkhand and Bihar over India.

It is found that the all-Bangladesh summer monsoon rainfall is positively correlated with the monsoon rainfall of Naga-Monipur-MizoramTripura $(c c=0.48)$, Sub-Himalayan West BengalSikkim $(\mathrm{cc}=0.46)$, Assam and Meghalaya (0.37) and Bihar Plateau (0.43) of India.

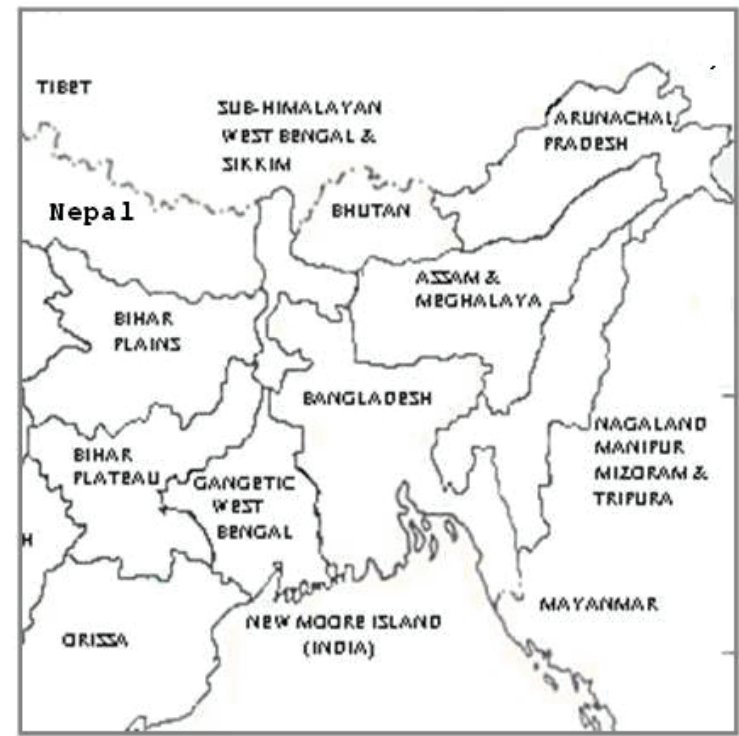

Figure 12: The location of Bangladesh and neighbouring sub-divisional region of India, Bhutan and Nepal.

The correlation with Bhutan shows relatively higher values, but due to too small length of the data series (10 years), the correlation coefficient is not significant enough and does not require any special interpretation at this stage. The above correlation features well indicates the spatial homogeneity of the monsoon activity over these areas lying close to Bangladesh and encircling around it from east, north and west. The correlation analysis shows negative correlation $(\mathrm{CC}=-0.33)$ between the monsoon rainfall of Bangladesh and Orissa. This negative correlation originates from the northsouth variations of the position and intensity of the monsoon trough and associated rainfall activities related with strong and weak monsoon years. Further, the depressions move to northwest while the monsoon trough passes over or near Orissa; and the depressions pass over Bangladesh, west Bengal and adjacent territories when the monsoon trough has more northerly position and passes over Bangladesh or nearby territories along the foot hills. During such conditions the land 
depressions are also formed over the foot hills when Bangladesh gets high rainfall along with northwestern territories of India, eastern Nepal and Bhutan.

Table-3: Correlation coefficients (CC) of all-Bangladesh summer monsoon rainfall (1961-2006) with sub-divisional summer monsoon rainfall over India (1961-2006), Bhutan (19901999), and Nepal (1961-1995).

\begin{tabular}{|c|l|c|}
\hline S.N. & \multicolumn{1}{|c|}{ Rainfall Region } & $\begin{array}{c}\text { Correlation } \\
\text { Coefficient (CC) }\end{array}$ \\
\hline 01 & Assam \& Meghalaya, India & 0.37 \\
\hline 02 & $\begin{array}{l}\text { Naga, Manipur, Mizora, \& Tripu- } \\
\text { ra, India }\end{array}$ & 0.48 \\
\hline 03 & $\begin{array}{l}\text { Sub-Himalayan West Bengal \& } \\
\text { Sikim, India }\end{array}$ & 0.46 \\
\hline 04 & Gangetic West Bengal, India & 0.25 \\
\hline 05 & Orissa, India & -0.33 \\
\hline 06 & Jharkhand, India & 0.06 \\
\hline 07 & Bihar, India & 0.43 \\
\hline 08 & Nepal & 0.04 \\
\hline 09 & Bhutan* & 0.50 \\
\hline
\end{tabular}

* The correlation value of Bhutan does not demand a special interpretation because of too small length (10 years) of the time series

\subsection{WET (ACTIVE) AND DRY (BREAK) SPELLS OF SUMMER MONSOON RAINFALL}

The intra-seasonal variability of Bangladesh rainfall activity showing the occurrence of wet and dry spells of summer monsoon has been investigated by using daily Bangladesh country average rainfall data from June to September, 2007 which was a highly active monsoon year (Figure 13). On an average 8-10 low pressure systems form over the Bay of Bengal during monsoon season. Summer monsoon rainfall over Bangladesh is characterized by significant wet (active) or dry (break) spell on a time scale of about two weeks (Prasad, 2005).

From the information as obtained from BMD, it is seen that 10 low pressure systems that includes 4 deep depressions, 1 depression, 3 well marked low pressure areas and 2 low pressure areas were formed over the Bay of Bengal during the period June - September 2007 (NCMRWF, 2008).

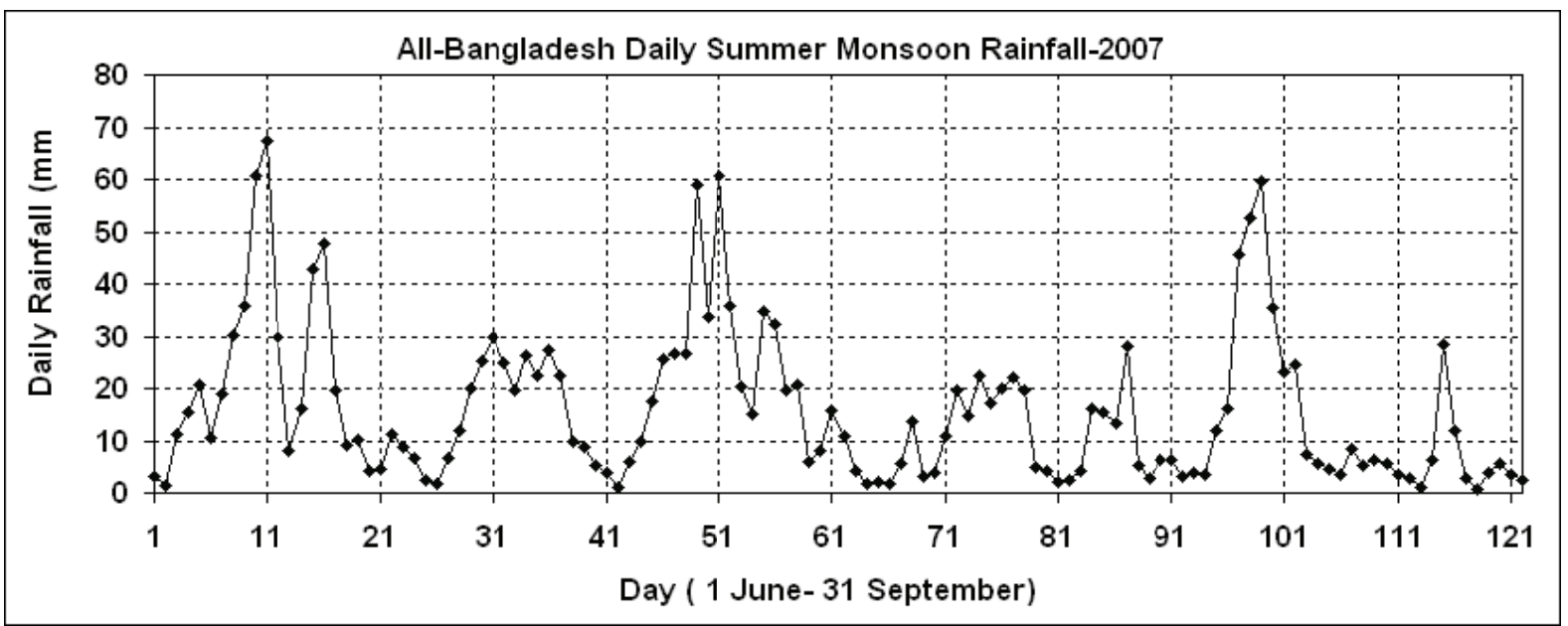

Figure 13: Wet and dry spells of summer monsoon rainfall over Bangladesh in 2007 
The temporal plot of the rainfall series clearly indicates the variability of the monsoon activity of different time scales. The low rainfall part of the plots identifies the weak or break monsoon activity and those with high rainfall belong to active phase of monsoon. There were three episodes with very high rainfall of around 60-68 mm/day. Such events were separated by around 40-50 days which correspond to long-term intra-seasonal variability of Median Julian type. The rainfall events of daily rainfall of 18-25 mm/day continuing for the period of 7 or more consecutive days in early July and middle of August are also prominent events of monsoon activities. Further investigation of the temporal distribution of the rainfall indicates that the rainfall variability has a number of timescales in or around 5-7, 10-14, 20-25 and 40-50 days. Similar results were also obtained for the monsoon rainfall analysis over Bhutan (Quadir, et al. 2005). The large scale variations of periods 20-25 and 40-50 days are linked with north-south variation of the position of monsoon trough as well as in the intensity of the pressure fields. The smaller scales of variations are linked with the formation of synoptic scale disturbances (lows and depressions) in the Bay of Bengal or over the land areas. In the year 2007, the formation of 10 disturbances over the period of 4 months (June-September) well explains the 10-14 days variations. The smaller scale variations of 5-7 days are related with the fluctuations of pressure fields in the monsoon trough also belongs to the synoptic scale variations of relatively lower intensity.

\section{CONCLUSION}

The following conclusions are drawn from the above results and discussion:

1) Annual profile of the monthly total country average rainfall shows a unimodal characteristic with highest in July followed by June and August and lowest in January followed by December and February.

2) The analysis of seasonal rainfall shows that the highest rainfall of $1769 \mathrm{~mm}(72 \%)$ occurs in monsoon season and lowest rainfall of $36.69 \mathrm{~mm}(1.5 \%)$ in winter season. The premonsoon and post-monsoon rainfall are 425 $\mathrm{mm}(17.3 \%)$ and 224.97 (9.2\%) respectively. Total annual country average rainfall of Bangladesh is $2456 \mathrm{~mm}$.

3) Summer monsoon rainfall widely varies over different parts of the country with lowest over central-west part (1200 $\mathrm{mm})$ and highest over southeast part $(3400 \mathrm{~mm})$ of the country followed by northeast part $(2800 \mathrm{~mm})$.

4) The summer monsoon rainfall for all of the stations has been expressed as percentage of annual rainfall and has been spatially distributed. Extreme southeast part of Bangladesh receives more than $82 \%$ of the annual rainfall during monsoon season which is the highest over Bangladesh. The lowest percentage of annual rainfall during monsoon season occurs at Srimangal which is about $60-62 \%$. Extreme northeast part of Bangladesh receives about 66\%. Extreme northwest and southwest part of Bangladesh receive about $72-74 \%$ of the annual rainfall. This indicates that Bangladesh is getting major portion of the annual rainfall during summer monsoon.

5) The country average annual total rainfall is $2470 \mathrm{~mm}$. All Bangladesh mean monsoon rainfall is $1769 \mathrm{~mm}$ ( $72 \%$ of annual), standard deviation is $210 \mathrm{~mm}$, and coefficient of variance is $11.8 \%$. Pre-monsoon, postmonsoon and winter obtains 17.4, 9.1 and 1.5 $\%$ of mean annual rainfall respectively. 
6) All-Bangladesh monsoon rainfall shows variability of varying intensities with 11 strong monsoon years having rainfall $\geq 10 \%$ of long period average and 8 weak monsoon years with rainfall $\leq-10 \%$ of long period average within the periods of 1961-2010.

7) The decadal distribution of rainfall shows that summer monsoon was in the wet decade during 1961-1970 and 1981-1990 and in the dry decade during the 1971-1980, 19912000 and 2001-2007. This clearly indicates the inter-decadal variability of monsoon rainfall.

8) Summer monsoon rainfall shows very small decreasing trend at the rate of about -0.53 $\mathrm{mm} /$ year. The pre-monsoon and annual rainfall trends are 1.74 and $1.92 \mathrm{~mm} /$ year respectively. It is found from the spatial distribution of the rainfall trends that the rainfall is increasing in the NW region at the rate of about 5-6 $\mathrm{mm} /$ year and $\mathrm{SE}$ region at the rate of about 3-4 $\mathrm{mm} /$ year and decreasing in the eastern Bangladesh at the rate of -2 to $-7 \mathrm{~mm} /$ year with largest negative trends over the east central region (about -6 to -7 $\mathrm{mm} /$ year).

9) The temporal plot of summer monsoon rainfall show the small scale inter-annual variability with time period of 2-3 years and 4-6 years and large scale variability with the time period of 9-14 years.

10) ENSO has an impact on monsoon systems on large subcontinent scale; the relationship is week in case of Bangladesh.

11) All-Bangladesh summer monsoon rainfall is positively correlated with the monsoon rainfall of Naga-Monipur-Mizoram-Tripura,
Sub-Himalayan West Bengal-Sikim and Bihar Plateau of India, and Bhutan. This clearly indicates the spatial homogeneity of monsoon rainfall activity over north-eastern region of South Asia.

12) The analysis of daily rainfall for the summer monsoon of 2007 shows that the intra-seasonal variation has characteristic timescales of 20-25 and 40-50 days. These large scale variations are connected with the occurrence of strong and weak spells of monsoon rainfall and caused by the north-south variations of the position of the monsoon trough and its intensity. The other scales of variations as revealed in the time series plots are 5-7 and 10-14 days. These variations are connected with the formation of the synoptic scale systems such as monsoon lows and depressions.

\section{ACKNOWLEDGEMENT}

The authors thank Dr. Janak Lal Nayava, the Chief Editor, Journal of Hydrology \& Meteorology, Nepal and the anonymous reviewers for their comments that improved the manuscript. Thanks are due to the Director of Bangladesh Meteorological Department and SAARC Meteorological Research Centre (SMRC) for providing the necessary data and facilities during this study.

\section{REFERENCES}

Ahasan, M. N., Mannan Chowdhury, M. A., and Quadir, D. A., 2008. Few aspects of the flood disaster caused by heavy rainfall over Bangladesh, Proceedings of SAARC Seminar on Application of Weather and Climate Forecasts in the Socio-economic Development and Disaster Mitigation, 
05-07 August, 2007, Dhaka, Bangladesh, $79-94$

Ahmed, R. and Karmakar, S., 1993. Arrival and withdrawal dates of the summer monsoon in Bangladesh. Int. J. Climatol., 13, 727-740.

Ahmed, R. 1989. Probabilstic estimates of rainfall extremes in Bangladesh during the premonsoon season. Indian Geogr. J., 64, 39-53.

Ananthakrishnan, R. and Soman, M. K.,1988. The Onset of the southwest monsoon over Kerala: 19011980, J. Climatology, 8, 283296.

Brammer, H., 1990. Floods in Bangladesh-I: Geographical background to 1987 and 1988 floods. Geogr. J., 156 (1), 12-22

Chowdhury, M.H.K., Pramanik, M.A.H., Quadir, D.A., and Nazlee Ferdousi, 2006. Study of meteorological parameter related to climate variability in Bangladesh, The Atmosphere, Vol. 3, 71-88.

Devkota, L.P., 2006. Rainfall over SAARC region with special focus on tele-connections and long range forecasting of Bangladesh monsoon rainfall, monsoon forecasting with a limited area numerical weather prediction system, Report No-19, Published by SAARC Meteorological Research Centre (SMRC), Dhaka, Bangladesh.

Hughes, R., Adnan, S. and Clayton, B.D., 1994. Flood plains or Flood Plans? A review of approaches to water management in Bangladesh, Research Advisory Service, Dhaka, Bangladesh.
Islam, M. N., 2008a. Understanding the rainfall climatology and detection of extreme weather events in SAARC region: Part IBangladesh. Report No-21, Published by SAARC Meteorological Research Centre (SMRC), Dhaka, Bangladesh.

Islam, M.N., 2008b. Studies of summer monsoon rainfall using regional climate model PRECIS, Report No-22, Published by SAARC Meteorological Research Centre (SMRC), Dhaka, Bangladesh.

Mannan, Md. Abdul, Samarendra Karmakar, 2008. Proceedings of SAARC Seminar on Application of Weather and Climate Forecasts in the Socio-economic Development and Disaster Mitigation, 05-07 August, 2007, Dhaka, Bangladesh, 95-115

Nahrin, Z., Munim, A.A., Begm, Q.N., and Quadir, D.A., 1997. Studies of periodicities of rainfall over Bangladesh, J. of Remote Sensing and Environment, 1, 43-54.

NCMRWF, Ministry of Earth Sciences (MoES), Government of India (January 2008). "MONSOON-2007: Performance of the T254L64 Global Assimilation Forecast System“, Report no. NMRF/MR/01/2008, Published by NCMRWF (MoES), A-50 Institute Area, Sector- 62, NOIDA, UP, INDIA 201307.

Prasad, K., 2005. Monsoon Forecasting with a Limited Area Numerical Weather Prediction System, Report No-11, Published by SAARC Meteorological Research Centre (SMRC), Dhaka, Bangladesh. 
Quadir, D.A., Shrestha M.L., Tariq Masood Ali Khan, Nazlee Ferdousi, Md. Mizanur Rahman and Md. Abdul Mannan, 2001. The Dynamic Changes of Climate in Bangladesh and the Adjacent Regions in Association with Global Warming. 4th International Conference on Mechanical Engineering, Dhaka, Bangladesh. Vol-II, 12-18

Quadir, Dewan A., Amirul Hossain, 2005. InterAnnual and Intra-Seasonal Variability of Temperature \& Precipitation of Bhutan,
Report No-13, Published by SAARC Meteorological Research Centre (SMRC), Dhaka, Bangladesh.

Website of Golden Weather Service, http:// ggweather.com/enso/oni.htm

Website of India Meteorology Department (IMD), http://www.imd.gov.in

Website of Indian Institute of Tropical Meteorology (IITM), http://www.tropmet.res.in 